\title{
Binding of Sulfobromophthalein (BSP) Sodium by Plasma Albumin. Its Role in Hepatic BSP Extraction*
}

\author{
Katharine J. Baker and Stanley E. Bradley \\ (From the Department of Medicine, Columbia University College of Physicians \& Surgeons, \\ and the Medical Service of the Presbyterian Hospital, New York, N. Y.)
}

When sulfobromophthalein (Bromsulphalein, $\mathrm{BSP}$ ) sodium was introduced some 40 years ago as a tool for the measurement of liver function, Rosenthal and White (1) reported that solution in serum completely prevented ultrafiltration of the dye through a collodion membrane. They suggested that binding of protein might make BSP and other substances with similar properties, such as bilirubin and rose bengal, more readily available for hepatic removal by preventing their loss in the urine. Although their observation has been repeatedly confirmed (2-7), precise quantitative data referable to BSP concentrations employed in clinical and physiological studies are still lacking. This is so, unfortunately, because the plasma proteins must be diluted 50 - to 100 -fold during examination of the dye-protein interaction by equilibrium dialysis or by ultrafiltration in order to minimize interference by oncotic pressure effects, changing protein concentrations, Gibbs-Donnan equilibria, and various membrane phenomena. To obtain measurable concentrations of BSP, one must work at molar ratios of dye-to-protein far in excess of those ever encountered in vivo. Since saturation of binding sites and alteration in binding capacity may occur at such high ratios, the resulting figures are of somewhat dubious physiological significance.

The information available does indicate that after addition to plasma in vitro or by intravenous injection, BSP promptly combines so avidly with albumin that almost none of it is detectable as a "free fraction." Definition of the mechanisms of hepatocellular transport must begin with precise values for the kinetic parameters of the BSP protein interaction to establish whether the initial movement of the dye from the blood to the cells can be accounted for by diffusion of the free frac-

* Submitted for publication June 15, 1965; accepted November 12, 1965.

Supported by a grant from the John A. Hartford Foundation, Inc. tion alone or whether free fraction and dye-protein complex are both implicated at physiologically meaningful concentrations. The availability of BSP labeled with radioactive sulfur has made it possible to re-evaluate plasma protein binding of BSP over an appropriate range of molar ratios. And, finally, the work of Scatchard and his associates (8-10) has provided an effective method of determining binding constants with greater accuracy from data obtained by equilibrium dialysis. The results of such a study are consistent with the conclusion that the free fraction is indeed so small under clinical and physiologic conditions that hepatic extraction may entail a substantial uptake directly from the plasma albumin.

\section{Methods}

The equilibrium dialysis method, described by Klotz, Walker, and Pivan (11) and modified by Taggart (12), was used to obtain data on the binding of BSP by plasma albumin, in molar ratios ( $\bar{\nu}=$ bound dye/protein) from 0.12 to 24 . Albumin and BSP solutions were made up in an isosmotic phosphate-chloride buffer, ionic strength 0.16 and $\mathrm{pH}$ 7.38. The dialysis membrane was Visking tubing, $\frac{1}{4}$ inch in diameter.

Liquid human serum albumin ${ }^{1}$ and crystalline bovine serum albumin 2 were used without further purification, either deionization or extraction. Protein concentrations were prepared by weight or volume, checked by micro$\mathrm{Kjeldahl}$ analysis for nitrogen content, and adjusted to 0.05 or $0.5 \mathrm{~g}$ per $100 \mathrm{ml}$ concentration. At these concentrations of albumin in buffer solution, errors resulting from the Donnan effect and osmotic gradient were minimized.

"Pure" standard BSP powder ${ }^{\mathbf{3}}$ was analyzed chromatographically for purity, with a mixture of $n$-butanol, glacial acetic acid, and water $(4: 1: 2$, vol/vol/vol) as the solvent. Three bands, all reacting to alkali like BSP, were demonstrable; two were very faint, one moving faster, the other slower, than the main component. Both substances were present in such trace amounts that further purification was deemed unnecessary. These impurities

1 Cutter Laboratories, Berkeley, Calif.

2 Armour Pharmaceutical Co., Kankakee, Ill.

${ }^{3}$ Hynson, Westcott and Dunning, Baltimore, Md. 
also appeared in trace amounts in two lots of ${ }^{35} \mathrm{~S}$-labeled $\mathrm{BSP}^{4}$ and were found to be radioactive. In addition, slight radioactivity could be detected in the chromatograph of $\mathrm{BSP}^{-35} \mathrm{~S}$ close to the point of application, the site at which contaminating sulfate would be expected although the material appeared to be "sulfate-free" on chemical analysis. The color development per unit weight was $97 \%$ of the standard BSP for the first lot (SA $6.5 \mu \mathrm{c}$ per $\mathrm{mg}$ ) and $92 \%$ for the second lot (SA $6.04 \mu \mathrm{c}$ per $\mathrm{mg}$ ) presumably as a result of contamination by a very small amount of sulfate and various inert substances. Computation of specific activities of the $\mathrm{BSP}-{ }^{35} \mathrm{~S}$ was based upon the colorimetric measurement of BSP in terms of the standard compound. Natural and synthetic conjugates with glutathione were prepared and purified by methods described previously (13). The lyophilized conjugates were checked by chromatography just before use to be certain that hydrolysis and degradation had not occurred. These substances were made up in the same buffer solutions as those used for the free dye.

The dialysis systems were set up with $2 \mathrm{ml}$ proteinbuffer solution (albumin, 0.05 or $0.5 \mathrm{~g}$ per $100 \mathrm{ml}$ ) inside the sac and $8 \mathrm{ml}$ buffer outside. Free dye or conjugates were introduced in appropriate concentrations into the solution outside the sac initially. In other experiments, equilibrium was approached with the dye and protein placed initially inside the sac. Dialysis tubes were sterilized, and precautions were taken to keep the systems free of mold. Each equilibrium level was determined in triplicate after dialysis at $37^{\circ} \mathrm{C}$ for 10 to 72 hours with 16 inversions an hour. Equilibrium was reached in control studies in 6 to 10 hours with protein omitted from the buffer solution inside the sac. Although 18 hours appeared to be sufficient for equilibration when protein solutions were included in the system, a 28-hour span was used routinely for high concentrations of BSP relative to protein, at which time the values were identical whether the dye was inside or outside the sac. When the molar ratio of "bound" dye to protein was less than 1.55 , however, it was necessary to extend dialysis to 72 hours. Even then, complete equilibrium was not achieved, and the dialyzate concentrations, obtained at the time when the dye was initially in the protein-free solution outside the sac, differed definitely from the dialyzate concentration when the dye was initially inside the sac; the former were always slightly in excess of the latter. To circumvent this difficulty, when the molar ratio was below 1.55 , we always obtained and averaged values for both. Repeated recoveries indicated that absorption by the sac was statistically insignificant.

BSP concentrations in all solutions except the dialyzates were measured colorimetrically with an 11.2-fold dilution in isotonic saline used routinely with appropriate blank corrections. Color development at $\mathrm{pH}>12$ read at $580 \mathrm{~m} \mu$ in a DU Beckman spectrophotometer permitted BSP determinations in albumin solutions without change in spectral absorption maxima of BSP or apparent loss of the dye due to alteration in protein optical density by alkalinization. Dialyzate BSP concentrations

4 Volk Chemical Co., Chicago, III. could therefore be determined to a level as low as 0.04 $\mathrm{mg}$ per $100 \mathrm{ml}$ without the standard dilution. At lower concentrations $\mathrm{BSP}^{\mathrm{3}}{ }^{\mathrm{S}} \mathrm{S}$ could be employed because its specific activity was unaffected by dialysis and protein binding. $\mathrm{BSP}^{-{ }^{35} \mathrm{~S}}$ was counted in quadruplicate in a thin window, gas flow, Geiger-Muller counter ${ }^{5}$ by the method of Isbell, Frush, and Peterson (14). Since even an infinitesimal quantity of radioactive sulfate could have introduced a serious error in calculation of the free fraction in the dialyzate at very low concentrations, corroborative colorimetric determinations were made twice at a molar ratio of 0.21 (points indicated as $X$ in Figure 1). On each occasion 15 dialyzates were pooled, once after dialysis with the BSP outside the sac and once with BSP placed inside the sac. The BSP in the dialyzates, after equilibration, was concentrated to levels that could be assayed spectrophotometrically after absorption on DEAE (from which BSP was found to be removed quantitatively) and elution in a small quantity of dilute alkali.

Twenty dialyzates unused for analysis (more than 100 $\mathrm{ml}$ ) were pooled, desalted, concentrated 200 -fold, and analyzed by bromophenol blue and Ninhydrin reactions after paper electrophoretic separations at $\mathrm{pH} 8.6$ and 1.9 to determine whether any protein moved across the membrane. No protein could be detected although a trace of Ninhydrin-positive material, which did not bind BSP, was observed. Because of its electrophoretic mobility at $\mathrm{pH} 1.9$, it was assumed to be a small peptide occurring as an impurity in the protein.

\section{Results}

BSP binding by bovine serum albumin was determined in triplicate on 43 occasions (Figure 1, points indicated by $\times$ and $\bullet$ ) over a range of molar concentration ratios from 0.12 to 13.6 molecules BSP per molecule of albumin. Liquid human serum albumin was employed in 32 studies at molar ratios from 1.2 to 24.5 . In most instances the albumin concentration was $0.05 \mathrm{~g}$ per $100 \mathrm{ml}$ ( $7.6 \mu$ moles per L), but for the lowest molar ratios a concentration of $0.5 \mathrm{~g}$ per $100 \mathrm{ml}$ was used to assure measurable levels of BSP in the dialyzate. At these molar ratios (0.12 to 0.61$) \mathrm{BSP}$ binding was in excess of $99.9 \%$, and BSP concentration in the dialyzate ranged from 0.0089 to $0.0434 \mu$ mole per L. Since the BSP/albumin molar ratios that usually obtain in physiological studies $(0.5$ to $30.0 \mathrm{mg}$ per $100 \mathrm{ml} \mathrm{BSP}$ and $5.0 \mathrm{~g}$ per $100 \mathrm{ml}$ albumin) range from 0.007 to 0.425 , the lowest ratios employed ( 0.12 to 0.48$)$ are obviously of particular importance. For this reason $\mathrm{BSP}^{35} \mathrm{~S}$ was used with bovine albumin to assure accuracy at these levels. On one occasion when

\footnotetext{
5 Nuclear-Chicago, Des Plaines, Ill.
} 


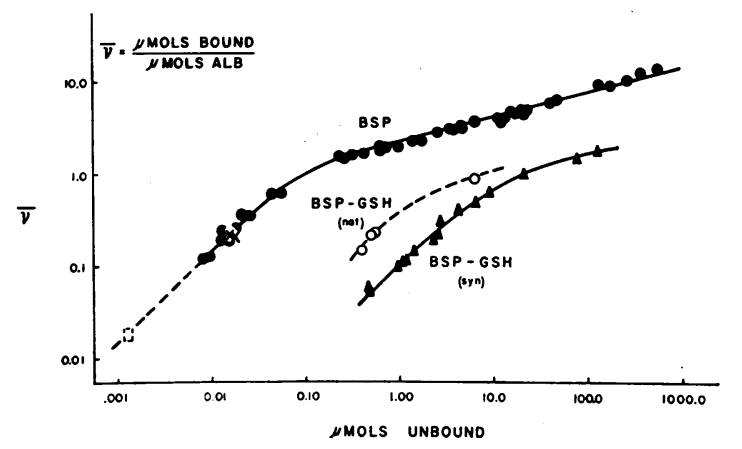

Fig. 1. Distribution of BSP-GSH (BromsulphaLEIN-GLUTATHIONE) AND BSP BETWEEN PLASMA ALBUMIN AND SOLVENT AFTER EQUILIBRIUM DIALYSIS. Data were obtained with BSP ( $\bullet$ and $\times$ ) or the major BSP-GSH conjugate [prepared synthetically $(\boldsymbol{\Delta})$ and by chromatographic separation from canine bile (O)] and bovine plasma albumin made up in isosmotic phosphate-chloride buffer, ionic strength 0.16 and $\mathrm{pH}$ 7.38. The molar concentration ratio ( $\bar{\nu}$, micromoles dye bound per micromole of albumin) is plotted logarithmically against the concentration of the unbound fraction of dye in the dialyzate. To minimize the difficulty in reaching equilibrium at very low BSP concentrations, we obtained two values at each level when the molar ratio of bound BSP (upper curve) to protein was less than 1.55 : one value when the dye was mixed in the protein solution inside the cellophane bag at the start of dialysis and a second when the dye was placed initially outside the bag in the protein-free buffer. See text for details. The dashed rectangle indicates a point corresponding to commonly encountered plasma concentrations of BSP (1 $\mathrm{mg}$ per $100 \mathrm{ml}$ ) and albumin $(5.0 \mathrm{~g}$ per $100 \mathrm{ml})$.

BSP was extracted from the dialyzate and measured colorimetrically, the value for the free fraction was found to conform with those obtained with the labeled compound.

BSP binding (i.e., $\bar{\nu}$, the molar ratio) increased progressively as BSP concentration in the solvent (free fraction) rose. When these variables were plotted against one another logarithmically, they described an "adsorption curve" with a slope that approached unity at very low BSP concentrations, consistent with the Langmuir adsorption isotherm, and fell off at higher values $(\bullet$, Figure 1$)$. Binding increased throughout the full concentration range without evidence of an approach to saturation of binding sites. At the highest concentrations it may be inferred that a change in protein configuration opened up additional sites in some regular manner. Human serum albumin showed a somewhat higher affinity for BSP than did bovine albumin. There was greater scatter, however, ow- ing to inaccuracies arising from preservative and impurities. For this reason, only the data obtained with crystalline bovine albumin were used for evaluation of binding constants and for presentation in Figures 1 and 2.

To derive binding constants that are applicable to the BSP-albumin interaction in the physiological range, one must analyze BSP equilibrium concentrations at the lowest determinable levels of the free fraction. For this purpose, the method developed by Scatchard and his associates (8-10) appears to be most appropriate. Scatchard has derived the following relationship, from the law of mass action, for the binding of a small molecule or ion to a number $\left(n_{i}\right)$ of sites on each protein molecule that have the same affinity $\left(k_{i}\right)$ toward the small molecule or ion. He designates such a group of sites as "class" (i). The observed molar ratio, $\bar{\nu}$, which equals moles of substance bound to total moles of protein, may then be expressed as a sum of the molar ratios for all the classes of sites to which the substance is bound, as follows:

$$
\bar{\nu}=\Sigma_{\mathrm{i}} \bar{\nu}_{\mathrm{i}}=\Sigma_{\mathrm{i}}\left[\mathrm{n}_{\mathrm{i}} \mathrm{k}_{\mathrm{i}} \mathrm{c} /\left(1+\mathrm{k}_{\mathrm{i}} \mathrm{c}\right)\right] .
$$

In the present study $c$ represents the concentration of unbound anion, and $k_{i}$, the "apparent" association constant for each site in class ${ }_{i}$, which is dependent on the conditions under which it is de-

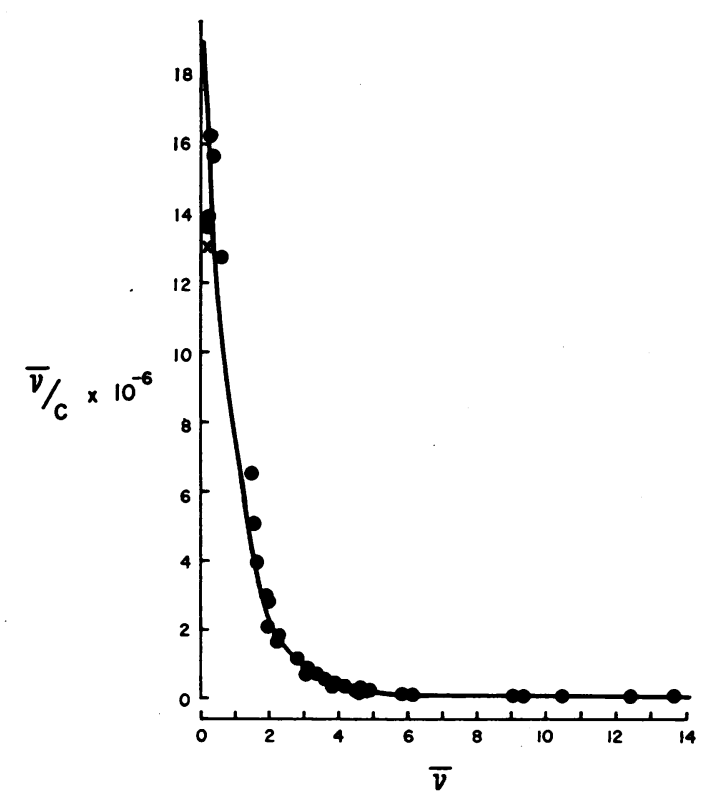

Fig. 2. Scatchard plot (9) For evaluation of bindING CONSTANTS FOR BSP AND ALBUMIN. $\bar{\nu}$, as in Figure 1 ; c, concentration of the unbound fraction of BSP. 
termined. [Appropriate corrections for electrostatic interactions, valence, the effect of the buffer, and the physical and physicochemical conditions at the binding sites would be necessary to determine the "intrinsic" constant of this reaction (15).]

By transposition and simplification Equation 1 becomes the linear equation,

$$
\bar{\nu} / \mathrm{c}=\mathrm{k}(\mathrm{n}-\bar{\nu}),
$$

for a single class of sites. From the plot of equilibrium values for $\bar{\nu} / \mathrm{c}$ and $\bar{\nu}$, values for $\mathrm{n}$ and $\mathrm{k}$ may be derived, since the $x$ intercept is $\mathrm{n}$ and the $y$ intercept $\mathrm{kn}$. This plot should yield a straight line if $\mathrm{k}$ is a constant. The data for $\bar{\nu} / \mathrm{c}$ and $\bar{\nu}$ obtained in this study for BSP are plotted in Figure 2. Inspection of Figure 2 indicates immediately that more than one binding class must be implicated, since the relationship is markedly curvilinear. The observed curve may be analyzed according to Scatchard and his associates $(8-10)$ by a process of successive approximations designed to yield the minimal number of rectilineal components. The best fit was obtained here on the assumption of three classes of binding sites in which $\mathrm{n}_{1}=1, \mathrm{k}_{1}=1.7 \times 10^{7} ; \mathrm{n}_{2}=2, \mathrm{k}_{2}=1.6 \times 10^{6} ;$ and $\mathrm{n}_{3}=14, \mathrm{k}_{3}=6 \times 10^{3}$.

The binding properties of the synthetic BSPglutathione conjugate differed significantly from those of "standard" BSP ( $\boldsymbol{\Delta}$, Figure 1). At all concentrations the free fraction of the conjugate was much higher than that of standard BSP, approximating $10 \%$ at molar ratios usually encountered in physiologic studies. As with unconjugated BSP, the curve conformed with the Langmuir adsorption isotherm at low concentrations. The curvilinearity suggests that several classes of binding sites were occupied $\left(\mathrm{n}_{1}=1, \mathrm{k}_{1}=1 \times 10^{5}\right.$; $\left.\mathrm{n}_{2}=2, \mathrm{k}_{2}=3 \times 10^{4}\right)$. The difference between the values for $k_{1}$ for dye and dye-conjugate indicates that the binding affinity of albumin for the unconjugated dye is at least 100 times greater than its affinity for the synthetic conjugate. When the same conjugate of BSP was isolated from the bile of the dog, it was found to behave differently $(\mathrm{O}$, Figure 1). This surprising result could not be accounted for by a chemical dissimilarity, since none was detectable in this and earlier studies either spectrophotometrically, chromatographically, or electrophoretically, before or after acid or alkaline hydrolysis. The "natural" conjugate ap- peared to differ from the synthetic compound not only in its affinity for albumin (some tenfold greater) but also in its greater instability in phosphate buffer. This instability and the difficulty of obtaining adequate quantities for study have delayed further analysis of such factors as isomerism. It may be concluded in any case, however, that the conjugation of BSP by glutathione significantly reduces its binding by protein.

\section{Discussion}

Although the techniques employed in these studies assured stable, reproducible conditions and yielded data relevant to the $\mathrm{BSP} /$ albumin molar ratios encountered in clinical and physiologic investigations, the derived constants must be interpreted with caution. Despite appropriate control of $\mathrm{pH}$, ionic strength, and temperature, buffered electrolyte solutions provide at best a poor approximation to the complexities inherent in plasma and tissue fluids. The magnitude of the apparent association constants for BSP and BSPglutathione conjugate, however, makes it unlikely that other anions in the body fluids, with the exception of the free fatty acids, and possibly bilirubin, compete effectively with the dye for binding sites upon the albumin molecules. The preparation of crystalline bovine plasma albumin used for equilibrium dialyses in this study was found to contain free fatty acids in a molar ratio of 0.99 , a value close to that observed in vivo. ${ }^{6}$ Any modification of the affinity of albumin for BSP by fatty acids in the circulating blood would be reflected, therefore, in the binding constants reported here. Technical factors such as buffer ion competition, electrostatic interactions between buffer and albumin, and cellophane surface effects might also have introduced error. Recoveries of dye from the dialysis sac were repeatedly complete at all but the lowest concentrations, and values obtained after equilibration in successive dialyses with BSP initially outside the bag on one occasion and inside on another were averaged at the very low concentrations to correct for any such error. The values for the constants applicable to the first class of binding sites $\left(\mathrm{n}=1\right.$ and $\left.\mathrm{k}_{1}=1.7 \times 10^{7}\right)$ are probably of the correct order of magnitude, there-

6 We wish to thank Dr. D. S. Goodman for making this analysis. 
fore, whereas the value for the other two definable classes may be less accurate. Fortunately, at the concentrations of BSP employed in physiological and clinical work, the first class of sites must be concerned almost exclusively with BSP binding, the others having negligible significance.

The extremely high affinity of BSP for serum albumin suggests that several intermolecular forces are involved. Since BSP is a sulfonated organic compound carrying a strong electronegative charge and the binding of $\mathrm{BSP}$ to protein is $\mathrm{pH}$ dependent, the primary intermolecular bond is presumably electrostatic. The dye-protein complex may be further stabilized by London-Van der Waals' forces between the nonpolar groups of dye and protein and by hydrogen bonding of the BSP phenolic groups. The sum of these bond energies could explain the apparent specificity and magnitude of the first association constants.

Electron microscopy has shown (16) that the sinusoidal epithelium may be freely permeable to the plasma proteins as a result of numerous fenestrations through which plasma may enter the perisinusoidal space of Disse. Ample opportunity is thus afforded the BSP-protein complex to come directly into contact with hepatic parenchymal cells. Certain considerations may be advanced to suggest that the protein-bound moiety might be involved to some extent in cellular uptake. Even if unbound BSP diffuses freely across the total epithelial surface, its concentration is probably too low relative to the velocity of perfusion and the transmural diffusion path length to account alone for the observed values of hepatic extraction in vivo.

This inference may be evaluated more precisely by computation of the BSP concentration change to be expected along the sinusoids solely as a result of outward diffusion of unbound BSP from plasma (BSP neither enters nor is bound by the red cells in dog or man). The concentration (C) of BSP in plasma (or whole blood) emerging from the sinusoids under these circumstances may be calculated on the basis of Fick's law of diffusion in terms of the concentration $\left(\mathrm{C}_{0}\right)$ in the plasma (or whole blood) entering the sinusoids, as follows :

$$
\mathrm{C}=\mathrm{C}_{0} \mathrm{e}^{-\mathrm{SD} \kappa / q x}=\mathrm{C}_{0} \mathrm{e}^{-\mathrm{D} \alpha / \alpha x}
$$

where D is the diffusion coefficient for BSP; $\kappa$, the ratio of concentrations of free to bound fractions; $\mathrm{S}$, the sinusoidal surface area across which diffusion occurs; $q$, the total rate of sinusoidal perfusion by plasma; $\alpha$, the ratio $\mathrm{q} / \mathrm{S}$; and $\mathrm{x}$, the diffusional path length. The maximal hepatic extraction of BSP (E) may be derived from Equation 3 as:

$$
\mathrm{E}=\left(\mathrm{C}_{0}-\mathrm{C}\right) / \mathrm{C}_{0}=1-\mathrm{e}^{-\mathrm{Dx} / a \mathrm{x}} .
$$

This equation may be evaluated for dog and man if it is assumed that the hepatic plasma flow per unit sinusoidal surface area $(\alpha)$ is the same in both and that the value for the association constant obtained with bovine serum albumin does not differ significantly from that for canine or human serum albumin. The value for $\alpha$ may be obtained from the average estimated hepatic blood flow in dogs ( $460 \mathrm{ml}$ per minute per $10 \mathrm{~kg}$ body weight) (17) with a hematocrit of $40 \%$ and from the dimensions of the sinusoidal bed in a $10-\mathrm{kg}$ dog with Mall's data (18) on the number $\left(2.64 \times 10^{9}\right)$ of sinusoids, an average sinusoidal diameter of $9 \mu$, and a mean length of $0.5 \times 10^{-1} \mathrm{~cm}$ computed from an estimate of sinusoidal blood volume in the dog derived by Goresky (19) from measurements of red cell transit time and flow. The computation of $\alpha$ also involves the assumption that outward diffusion across the sinusoidal wall and the space of Disse begins at the stationary plasma boundary layer and that the sinusoidal surface may therefore be defined as the surface of a cylindrical tube. The use of plasma flow rather than whole blood flow in this computation implies that erythrocytes do not exclude plasma from the sinusoidal surface at any point during perfusion. It seems probable, however, that this view is in error and that the surface available for diffusion is effectively reduced by some function of the hematocrit. The assumption that the hematocrit does not materially affect diffusional loss, therefore, probably results in too large a value for diffusion. Finally, diffusion is assumed to occur down a concentration gradient equal to the concentration in the blood at each point along the sinusoid, i.e., the parenchyma behaves as an infinite "sink" that takes up BSP so effectively that the concentration in the layer of fluid at the cell surface may be taken as zero. On these assumptions the maximal BSP 
extraction,

$$
\mathrm{E}=1.0-\mathrm{e}^{-0.188}=1.0-0.828=0.160,
$$

for both man and dog when $\alpha$ is taken as $1.23 \times$ $10^{-5} \mathrm{ml}$ per second per $\mathrm{cm}^{2}$ of sinusoidal surface area ; $\mathrm{D}$, as $3 \times 10^{-6} \mathrm{~cm}^{2}$ per second, from the molecular weight of BSP and the Einstein equation; $\kappa$, as $7.7 \times 10^{-5}$ for a plasma albumin concentration of $5 \mathrm{~g}$ per $100 \mathrm{ml}$; and $\mathrm{x}$, as $10^{-4} \mathrm{~cm}$, the combined thickness of the endothelial cells and the perisinusoidal space (20).

Even when due allowance is made for probable species differences and errors in anatomical measurements, this value for $E$ contrasts strikingly with values as high as 0.915 reported in man (21) and 0.50 in the $\operatorname{dog}(17)$. This value is also consistent with the observation by Brauer and Pessotti (6) that BSP extraction by the perfused rat liver changes from 0.957 to 0.147 , on the average, when bovine plasma albumin is added to the perfusate (bicarbonate-buffered Locke's solution containing BSP, $5.0 \mathrm{mg}$ per $100 \mathrm{ml}$ ) to bring the protein concentration to $5 \mathrm{~g}$ per $100 \mathrm{ml}$. It seems reasonable, therefore, to conclude that a substantial fraction of BSP entering the parenchymal cells in vivo is transported to them from the blood in combination with plasma albumin. If no more than 0.16 of an extraction of 0.90 can be accounted for by the unbound moiety, it may be shown on the basis of the diffusion coefficient for albumin and the Fick equation that no more than 0.002 of the sinusoidal surface need be permeable to albumin, provided all the protein-bound BSP traversing the endothelium is removed by the parenchymal cells. In view of the extent of the gaps between the endothelial cells that are demonstrable by electron microscopy (16), this value would seem to be an underestimate of the area actually open to the plasma proteins.

The movement of protein-bound BSP into the hepatic cells presents a different problem. There is no evidence that albumin (or any of the other plasma proteins) is taken up with the dye. Brauer and Pessotti (6) have shown that BSP is avidly absorbed by rat liver slices from a phosphatebuffered Kreb's solution, even when bovine plasma albumin has been added to the medium in concentrations up to $5 \mathrm{~g}$ per $100 \mathrm{ml}$. Uptake by the slice is appreciably diminished in the presence of protein, however, and they point out that "the mag- nitude of this effect, as well as the shape of the saturation curves on repetitive transfer [of slices] through protein-free media suggests that the effective dissociation constant of the BSP intracellular protein complex is larger than that of the albuminBSP complex." Andrews and Del Rio Lozano (22) and Barber-Riley (23) have brought forward evidence supporting this contention. It follows, therefore, that movement of bound BSP into the cells probably cannot be ascribed to a rapid transfer from albumin as a result of greater affinity of, and preferential absorption by, the cellular proteins. Instead, it must be inferred that dissociation of the BSP-albumin complex is augmented in some manner by contact with the enormous surface provided within the perisinusoidal space by the hepatocellular microvilli. Inasmuch as the association constant for BSP-glutathione is consistent with a free fraction at least ten times greater than that for BSP, formation of the conjugate at the cell boundary would provide one means by which dissociation could be enhanced. Further study of the cellular location of the process of glutathione conjugation is needed to assess this possibility.

\section{Summary}

Binding of sulfobromophthalein (BSP) sodium and its major glutathione conjugate by human and bovine plasma albumin has been studied by equilibrium dialysis over a wide range of concentrations. Radioactive sulfur-labeled BSP was used in the study of binding at molar concentration ratios of BSP and albumin approaching those encountered in vivo. Analysis of the data demonstrates that less than $0.1 \%$ of BSP and $1.0 \%$ of its conjugate are unbound as free fractions at plasma concentrations employed in clinical and physiologic studies. Calculation indicates that hepatic extraction of unconjugated BSP by man and experimental animals probably entails hepatocellular uptake of the dye directly from the BSP albumin complex that has moved across the sinusoidal wall.

\section{Acknowledgments}

We wish to express our deep gratitude to Drs. D. M. Gomez, D. S. Goodman, G. Scatchard, and H. O. Wheeler for advice and criticism during the course of these studies. 


\section{References}

1. Rosenthal, S. M., and E. C. White. Studies in hepatic function. VI. A. The pharmacological behavior of certain phthalein dyes. J. Pharmacol. exp. Ther. 1924, 24, 265.

2. Robinson, G. L. A study of liver function and plasma volume in chronic rheumatism by means of phenol-tetrabrom-phthalein sodium sulphonate. Ann. rheum. Dis. 1942-43, 3, 207.

3. Bradley, S. E., F. J. Ingelfinger, G. P. Bradley, and J. J. Curry. The estimation of hepatic blood flow in man. J. clin. Invest. 1945, 24, 890.

4. Ingelfinger, F. J., S. E. Bradley, A. I. Mendeloff, and P. Kramer. Studies with Bromsulphalein: I. Its disappearance from the blood after a single intravenous injection. Gastroenterology 1948, 11, 646.

5. Andrews, W. H. H., and T. G. Richards. The activity of bile salts and certain detergents on the hepatic storage and protein-binding of sulphobromophthalein. Quart. J. exp. Physiol. 1960, 45, 275.

6. Brauer, R. W., and R. L. Pessotti. The removal of sulphobromophthalein from blood plasma by the liver of the rat. J. Pharmacol. exp. Ther. 1949, 97, 358.

7. Bennhold, H., H. Ott, and M. Wiech. Utber den Bindungsunterschied lebergängiger Substanzen an die Serumeiweisskörper. Dtsch. med Wschr. 1959, $75,11$.

8. Scatchard, G. The attractions of proteins for small molecules and ions. Ann. N. Y. Acad. Sci. 1949, $51,660$.

9. Scatchard, G., I. H. Scheinberg, and S. H. Armstrong, Jr. Physical chemistry of protein solutions. IV. The combination of human serum albumin with chloride ion. J. Amer. chem. Soc. 1950, 72, 535.

10. Scatchard, G., J. S. Coleman, and A. L. Shen. Physical chemistry of protein solutions. VII. The binding of some small anions to serum albumin. J. Amer. chem. Soc. 1957, 79, 12.
11. Klotz, I. M., F. M. Walker, and R. B. Pivan. The binding of organic ions by proteins. J. Amer. chem. Soc. 1946, 68, 1486.

12. Taggart, J. V. Protein binding of $p$-aminohippurate in human and dog plasma. Amer. J. Physiol. 1951, $167,248$.

13. Javitt, N. B., H. O. Wheeler, K. J. Baker, O. L. Ramos, and S. E. Bradley. The intrahepatic conjugation of sulfobromophthalein and glutathione in the dog. J. clin. Invest. 1960, 39, 1570.

14. Isbell, H. S., H. L. Frush, and R. A. Peterson. Tritium labeled compounds. I. Radio assay of tritium labeled compounds in "infinitely thick" films. Journal of Research of the National Bureau of Standards 1950, 63A, 171.

15. Goodman, D. S. The interaction of human serum albumins with long-chain fatty acid anions. $\mathrm{J}$. Amer. chem. Soc. 1958, 80, 3892.

16. Fawcett, D. W. Observations on the cytology and electron microscopy of hepatic cells. J. nat. Cancer Inst. 1955, 15, 1475.

17. Fisher, B., C. Russ, R. G. Selker, and E. J. Fedor. Observations on liver blood flow. Its relationship to cardiac output in anesthetized and unanesthetized animals. Arch. Surg. 1956, 72, 600.

18. Mall, F. P. A study of the structural unit of the liver. Amer. J. Anat. 1906, 5, 227.

19. Goresky, C. A. A linear method for determining liver sinusoidal and extravascular volumes. Amer. J. Physiol. 1963, 204, 626.

20. Aterman, K. The structure of the liver sinusoids and the sinusoidal cells in The Liver, Ch. Rouiller, Ed. New York, Academic Press, 1963, vol. 1, p. 61.

21. Bradley, S. E., F. J. Ingelfinger, and G. P. Bradley. Hepatic circulation in cirrhosis of the liver. Circulation 1952, 5, 419.

22. Andrews, W. H. H., and I. del Rio Lozano. Some factors affecting the passage of sulphobromophthalein into and out of hepatic parenchymal cells. Quart. J. exp. Physiol. 1961, 46, 238.

23. Barber-Riley, G. Proportion of sulphobromophthalein protein-bound within incubated rat liver slices. Nature (Lond.) 1962, 194, 184. 